\title{
Momentos estáticos y estéticos de Rosalía de Castro en el espacio urbano de A Coruña
}

\author{
Lucía GARCÍA VEGA \\ lugarvega@gmail.com
}

\begin{abstract}
Resumen
El hecho notorio de estar reescribiendo constantemente $y$, por tanto, actualizando la biobibliografía de Rosalía de Castro (1837-1885) parece ser un motivo suficiente para perfilar un poco más, si cabe, aquellos aspectos omitidos o tratados de manera limitada en los diversos y necesarios estudios críticos sobre ella. Por ello, nos proponemos a lo largo de las líneas siguientes mostrar la importancia de la relación recíproca entre la escritora y la ciudad de A Coruña, demasiadas veces pasada por alto.
\end{abstract}

Palabras clave: Rosalía de Castro, A Coruña, literatura de mujer, Posromanticismo, espacio urbano y literatura.

Title: Static moments and aesthetic of Rosalía de Castro in the urban space of A Coruña

\section{Abstract}

The notorious fact of being constantly rewritten and thus updating the biobibliography of Rosalía de Castro (1837-1885) seems to be a sufficient reason to profile a bit more, if possible, those aspects omitted or poorly treated in the various studies and necessary critical of it. Therefore, we propose along the following lines show the importance of the interaction between the writer and the city of A Coruña, too often overlooked.

Keywords: Rosalía de Castro, A Coruña, women's literature, postRomanticism, space of the city and literature.

\section{Índice}

1. Introducción

2. Estancias de Rosalía de Castro en la ciudad de A Coruña

2.1. 1859, de popa a proa. De Santiago de Compostela a A Coruña

2.2. 1861 y 1871 , de estribor a babor. De Madrid a A Coruña

2.3. Amara, la auténtica hija del mar. Amaro, el navegante

3. Jardín de San Carlos, lugar de inspiración

4. John Moore: ¿héroe o villano?

5. Conclusiones

\section{Introducción}

A mi hermana María Rocío, por infinitos motivos,

El lingüista Mijaíl Bajtin considera un cronotopo "la conexión esencial de las relaciones temporales y espaciales asimiladas artísticamente en la literatura" (Bajtin 1989: 237). Convendría preguntarse ahora 
qué ocurriría si intentáramos dar funcionalidad a este concepto con el fin de conseguir identificar los diferentes modos de uso temporal del espacio coruñés, a poder ser conservando la conexión bajtiniana, en los referentes literario y biográfico de Rosalía de Castro. Incluso semeja lícito ir más allá y ser un poco más ambiciosos en lo epistemológico, con el propósito de lograr la comprobación relativa a si el tiempo adquiere visibilidad y si el espacio se intensifica desde el punto de observación artístico, según teoriza el filólogo ruso.

Puesto que el cariz estructural de este artículo podría atender a plurales posibilidades, en esta ocasión optamos por presentar inicialmente aquellas cuestiones relacionadas con la dimensión estancial de la escritora en el espacio urbano coruñés. Esto nos proporcionaría un emplazamiento privilegiado ante alguna que otra deducción diáfana acerca del hilo conector existente entre algunos instantes biográficos y el lugar referido.

A continuación nuestro proyecto pasaría por indagar algo más sobre el vínculo que parece haber entre el momento creativo de la poeta a la hora de solidificar los versos del texto "Na tomba do xeneral inglés Sir John Moore", incluido en el poemario Follas novas (1880), y la vaporosa y presumible influencia ejercida por el propio ámbito urbano coruñés en el resultado lírico en cuestión.

\section{Estancias de Rosalía de Castro en la ciudad de A Coruña}

Hasta donde la documentación sobre la biografía rosaliana nos ha permitido llegar, se puede decir que la escritora permaneció ${ }^{1}$ en $A$ Coruña en tres momentos de su vida. Si nos ubicamos en el centro de una figurada rosa de los vientos, la primera estancia tuvo lugar en 1859, cuando Rosalía de Castro, ya casada e instalada en Galicia, partía del suroeste rumbo al noroeste. Dos años más tarde, situada al este - primero en Simancas (Valladolid) y después en Madrid- de su Edén -Galicia-, regresaba al oeste, ruta que repetiría diez años después, es decir, en 1871. Esta última fue la etapa coruñesa más larga y, probablemente, la última, que se conozca por ahora, en su carta de navegación.

\subsection{9, de popa a proa. De Santiago de Compostela a A Coruña}

Por sorprendente que parezca, no son pocos los estudios críticos que demuestran cierta asepsia a la hora de registrar o de sugerir el dato

\footnotetext{
1 Es necesario advertir que las estancias fueron variables en cuanto a duración temporal se refiere. En el caso de 1861 resulta más apropiado el uso del verbo pernoctar, en vez de residir, en la ciudad, toda vez que estuvo allí solo una noche, tal y como ella misma relataba en una carta y a la que aludiremos más adelante.
} 
referente a que Rosalía de Castro se trasladó en 1859 de Santiago de Compostela ${ }^{2}$ a A Coruña para vivir una breve temporada allí.

En este punto en concreto no se hace necesario ni leer entre líneas ni diseñar un plan estratégico a base de cábalas y sospechas. Si seguimos las evidencias que afloran a la superficie de su ámbito biográfico certificado, no es extraño encontrar con cierta rapidez una respuesta al motivo de esta nueva residencia; esto es, el acto de abnegación personal que Rosalía de Castro, compañera de travesía vital del polifacético coruñés Manuel Martínez Murguía (1833-1923) ${ }^{3}$, quiso tener hacia su esposo, algo que, desde fuera, parece ser una manifiesta y constante línea tendente de generosidad en sus coordenadas vitales.

Sobre esta estancia sabemos que fue al poco tiempo de haber debutado en su gravidez y que estuvo en compañía de la pequeña Alejandra ${ }^{4}$, de su madre y de una nodriza. En aquellos momentos Manuel Murguía trabajaba en el Diario de La Coruña ${ }^{5}$, periódico en el que el coruñés estuvo alrededor de tres meses. De aquí marchó a Vigo a finales de ese mismo año, en donde también estuvo acompañado por la escritora.

Tampoco habría que descartar otro dato relacionado con la biografía del historiador y que le vinculaba con la ciudad coruñesa en fechas no muy lejanas. El 3 de agosto de 1858, la Dirección de Instrucción Pública le autorizaba a investigar la documentación existente sobre la historia de Galicia en el Archivo de A Coruña, según él mismo explicaba años después en un breve escrito acerca del estado en que se encontraba dicho Archivo ${ }^{6}$. Entra dentro de lo

${ }^{2}$ Sobre la relación de la escritora con la ciudad compostelana, véase García Vega (2011).

3 Su madre se dirigía al santuario de la Virgen de A Pastoriza (Arteixo, A Coruña) cuando se le adelantó el parto. Según hemos podido comprobar en la partida de bautismo correspondiente, nació en la casa de Antonio Pan, situada en el lugar de Froxel y perteneciente a la parroquia de San Tirso de Oseiro (Arteixo, A Coruña). Parece probable que en homenaje a este señor fuese bautizado también con el segundo nombre de Antonio. Aunque hoy resulte algo anecdótico, los padres del historiador contrajeron matrimonio por el rito católico con posterioridad a su nacimiento, situación atípica en el año 1833. En el margen izquierdo de esta partida bautismal se concreta que el 22 de julio los padres se casaron y que "legitimaron la prole". Archivo Histórico Diocesano de Santiago de Compostela. Parroquia de San Tirso de Oseiro. Libro 6 de Bautizados (1817-1852).

${ }^{4}$ Primera hija del insigne matrimonio. Nació en 1859 en Santiago de Compostela y falleció en A Coruña, curiosamente cien años después del nacimiento de su madre.

5 Llevaba por subtítulo Periódico literario, científico e industrial. Publicaba editoriales y sueltos, extractos oficiales, noticias nacionales y extranjeras, variedades, gacetillas, boletín religioso, noticias mercantiles, anuncios y folletín. Fue uno de los diarios gallegos con mayor número de suscripciones (Soto 1982: 56; Santos 1990: 125-126).

${ }^{6}$ Se trata de una Memoria relativa al Archivo Regional de Galicia y que aparece firmada por Manuel Murguía el 20 de marzo de 1871, por lo tanto, realizada al poco 
posible que se hubiese trasladado en el verano de 1859 a esta ciudad, quizá compaginando la investigación referida con su trabajo en el periódico coruñés aludido.

Asimismo, lo que parece distanciarse de la mera especulación es que, en esta época en la que se produjo la primera estancia probada, la reputada escritora ya no era una desconocida en la ciudad de A Coruña. Dos años antes, la revista coruñesa El Iris de Galicia publicaba la que, a falta de otras informaciones que demuestren lo contrario, semeja ser la primera reseña en Galicia sobre Rosalía de Castro:

Por último, tengo que anunciar á ustedes una interesante novedad para la honra del país. Galicia cuenta entre sus hijos una notable poetisa. Tengo á la vista un cuaderno titulado La Flor, poesías de Doña Rosalía Castro, impreso en Madrid, donde reside su autora. A juzgar por las bellísimas composiciones que contiene, por la armonía fácil y sencilla de su metrificación, aseguramos que las dotes poéticas que adornan á dicha señorita, con cuya amistad me honro, son mas que suficientes a conquistar un nombre en la historia de su patria, y á merecer un lugar al lado de los que hoy son gala de nuestra literatura nacional. (El Iris de Galicia, 13/5/1857)

\subsection{1 y 1871, de estribor a babor. De Madrid a A Coruña}

La excelsa compostelana le exponía a Manuel Murguía las ganas de quedarse en A Coruña en 1861, al regresar a Santiago de Compostela después de haber estado una temporada con él en Madrid ${ }^{7}$, aspecto que estaría demostrando que, por estas fechas, sentía bastante atracción hacia este lugar ribereño:

La Coruña estaba hermosísima. Una temporada de primavera y un sol brillante. Estaba por quedarme ya en ella. Si aquí me fuese mal, allá me iba, pues ya tenía un sitio muy bueno, y bien amueblado, donde por tres duros al mes me ponían servicio, habitación y planchado. (Castro 1993: 2, 601-602)

Este viaje de retorno a Galicia al que aludimos lo realizó a mediados de diciembre de 1861. Sabemos que el día 14 ella, su madre y su hija Alejandra llegaron a A Coruña a las doce de la noche, y que permanecieron allí parte del día 15, fecha en la que ya estaban en Santiago de Compostela:

tiempo de incorporarse a su nuevo puesto en A Coruña, tras haber cesado como Jefe de tercer grado del Archivo de Simancas (Valladolid).

7 Para más datos acerca de los aspectos biográficos de la escritora en la ciudad madrileña, véase García Vega (2010). 
Llegamos a La Coruña a las doce de la noche, aburridas y disgustadas, porque desde cerca de Betanzos hasta llegar a La Coruña, la niña vino con un cólico, que le pasó porque Dios lo quiso, pues con nada pudimos acudirle: pero como es tan fuerte, sanó sin remedio alguno. [...]

Así llegamos a La Coruña, donde no quisimos cenar nada, tomamos al otro día otro café antes de almorzar, a pesar de lo cual nos llevaron en la dichosa Coruña, por dormir y el café, 24 reales. (Castro 1993: 2, 601)

Una década aproximadamente tuvo que pasar para que Rosalía de Castro volviese a estar en A Coruña, según los datos evidenciados que hay en la actualidad. Sabido es que Manuel Murguía fue cesado de su puesto como Jefe de tercer grado del Archivo vallisoletano de Simancas el 10 de octubre de 1870. Su siguiente destino profesional fue el Archivo Regional de Galicia en la ciudad de A Coruña, cargo del que tomó posesión el 1 de diciembre de 1870. Dos años después, suscribía el padrón de vecinos y señalaba que llevaba viviendo en $A$ Coruña dos años; por lo tanto, las fechas se ajustan a lo creíble.

No obstante, la escritora y sus dos hijas Alejandra y Aura ${ }^{8}$ residieron en Madrid como mínimo hasta el 9 de enero de 1871, noticia fácil de verificar a través de una carta enviada desde la capital estatal y en la que se hace alusión a su presencia allí (Naya 1953: 21-22).

Con todo, Rosalía de Castro estaba instalada ya en A Coruña el 5 de marzo de 1871, y emprendía al lado de su esposo e hijas su etapa biográfica coruñesa más dilatada y productiva. De tal forma en el epistolario conocido de Manuel Murguía se halla una carta enviada desde Madrid con esta data y en la que el remitente ${ }^{9}$ estaba al tanto del viaje de vuelta a Galicia de la escritora.

En la actualidad sabemos que la familia habitó en el piso segundo del número 3 de la calle del Príncipe ${ }^{10}$, un capilar urbano que se ramifica desde el centro neurálgico de la zona conocida como Pescadería. Posee la plusvalía, entre otras ${ }^{11}$, de ser una de las primeras calles mencionadas en documentos históricos coruñeses.

A nada que se practique una revisión del calendario, resulta asequible plasmar una deducción irrefutable: Rosalía de Castro

\footnotetext{
${ }^{8}$ Nacida en el revolucionario año de 1868 en Santiago de Compostela.

9 Se trata de un gran amigo del historiador, el compostelano Ramón Rúa Figueroa (1825-1874), ingeniero de minas y colaborador periodístico. Curiosamente estaba emparentado con la escritora coruñesa Emilia Pardo Bazán (1852-1921).

10 A raíz de la revolución de 1868 , este lugar urbano cambió temporalmente de nombre y pasó a ser calle Juan de Padilla.

11 En esta calle del Príncipe falleció la poeta, novelista y académica coruñesa Francisca Herrera Garrido (1869-1950). Al ser elegida numeraria de la Academia Gallega en 1945, preparó un documentado discurso sobre Rosalía de Castro para su recepción como miembro. Murió sin llegar a tomar posesión de su sillón académico.
} 
estaba embarazada de los gemelos Gala y Ovidio $^{12}$ al arribar en A Coruña. Asimismo, parece que no gozó de buena salud, según se puede constatar en varias cartas enviadas a su esposo en las datas siguientes y a través de las que se expresaba un reiterado deseo de mejora. Y a mayor abundamiento conocemos la noticia relativa a que las hijas del célebre matrimonio se vieron afectadas por una dolencia pasajera en torno al 14 de mayo de 1871 , dato que nos permite situar a toda la familia en A Coruña en torno a estas fechas.

Otra cuestión que, dada su importancia, conviene tener en cuenta es la concerniente a que, como mínimo, desde finales de noviembre de 1871, la hija mayor del matrimonio, Alejandra, se trasladó a vivir a Santiago de Compostela, en donde residió en la casa de su abuelo paterno, el farmacéutico Juan Martínez. Existen diversas cartas enviadas por ella al domicilio coruñés por esta época (Pociña y López 2000: 64-65).

\subsection{Amara, la auténtica hija del $\operatorname{mar}^{13}$. Amaro, el navegante}

Si imaginamos un simbólico viaje a través del tiempo, en 1873 hallamos otra veta reveladora de dos inequívocos episodios consustanciales a la biografía de la escritora y que certifican a las claras su permanencia en la ciudad de A Coruña. Se trata del nacimiento, en la casa número 3 de la calle del Príncipe, y del bautizo, en la iglesia parroquial de Santa María y Santiago, de su quinta hija, Amara, que tuvieron lugar el 17 de julio y el 17 de agosto, respectivamente. Su inscripción eclesiástica reza así:

El diecisiete de agosto de 1873, bauticé a una niña, que nació en la casa número $3-2^{\circ}$ piso del Príncipe, hoy Padilla (El Comunero). Le puse el nombre de Amara, Honorata, Ma del Carmen, nacida el diecisiete de julio anterior. Hija legítima de D. Manuel Murguía, natural de Santa María de Pastoriza (La Coruña) y de Da Rosalía Castro, natural de la Parroquia del Hospital de Santiago. Abuelo paterno, D. Juan Martínez Castro, natural de San Benito de Santiago; y de $\mathrm{D}^{a}$ Concepción Murguía, natural de Ayerzún (Guipúzcoa), difuntos; y materna $\mathrm{D}^{\mathrm{a}}$ Teresa Castro, natural de Iria Flavia. Madrina, Alejandra Martínez Murguía, hermana de la bautizada. Firma la partida el Ecónomo de la Parroquial de Santiago, Estanislao de la Peña González. (Pociña y López 2000: 70)

Ya fallecida Rosalía de Castro, Amara se instaló con el resto de la familia en A Coruña, en donde parece ser que llevaba una vida tranquila y bastante apartada. Apenas salía a la calle, salvo para ir a

\footnotetext{
${ }^{12}$ Nacieron en Lestrobe (Dodro, A Coruña) en el verano de 1871.

13 Utilizamos la letra cursiva para resaltar el juego de palabras, en clara referencia a la primera novela publicada por Rosalía de Castro en 1859, ambientada en Muxía (A Coruña) y titulada La hija del mar.
} 
la cercana iglesia de San Nicolás, algo que tenía por costumbre hacer a diario y a horas muy tempranas. Por lo visto, no era infrecuente verla asomada en uno de los balcones de su domicilio, en el número 14 de San Agustín (Naya 1974: 41; 1998: 160).

La única hija del ilustre matrimonio De Castro-Murguía nacida en A Coruña falleció de forma súbita en diciembre de 1921, a consecuencia de un "colapso cardíaco" (vid. El Ideal Gallego, 30/12/1921). Era la cuarta vez ${ }^{14}$ que Manuel Murguía tenía que pasar por la dramática situación de sobrevivir, en este caso, a una hija. Un periódico de A Coruña publicaba la noticia necrológica que mostramos a continuación:

La señorita Amara Murguía de Castro falleció víctima de rápida dolencia, para la cual fueron inútiles los auxilios de la ciencia y los cariños de su padre y hermana [...]. La finada era un tesoro de bondades y de dulzura, que adquirían mayor relieve en su carácter angelical y en su trato todo amabilidad y todo inteligencia. (El Norte de Galicia, 30/12/1921)

Amara fue enterrada en el cementerio coruñés de San Amaro ${ }^{15}$, un espacio inevitablemente relacionado con la gran mayoría ${ }^{16}$ de los miembros de la familia de Rosalía de Castro.

Por otro lado, parece apropiado fijar nuestra atención en el valor polisémico que el nombre de Amaro parece obtener en el contexto de estas líneas. En este sentido, convendría aludir a la leyenda del abad y navegante que realiza un maravilloso viaje ${ }^{17}$ por

${ }^{14}$ En vida de Rosalía de Castro fallecieron dos hijos en Santiago de Compostela, Adriano (1875-1876) y Valentina (1877). Ovidio, reconocido pintor, moría en enero de 1900 en A Coruña a consecuencia de la tuberculosis.

${ }^{15}$ Obra del arquitecto compostelano Fernando Domínguez Romay. El trazado del camposanto dio comienzo en el año 1781 -una lectura palindrómica de éste nos indica el mismo instante cronológico en que Rosalía de Castro firmaba el poema dedicado a John Moore-. Está estructurado en tres áreas, una civil, otra religiosa y la denominada zona británica. En esta última se encuentran los restos mortales de los soldados británicos fallecidos en la Batalla de Elviña (1809) -a la que la poeta hace mención en su texto lírico dedicado a Moore-; se trata de un sector acotado y cerrado al público bajo llave que custodia el cónsul británico encargado de realizar el servicio diplomático correspondiente en la ciudad.

${ }^{16}$ El famoso historiador dejaba este mundo en 1923, en la casa que ocupaba en San Agustín, como hemos indicado. A él le siguió su hija Alejandra en 1937. En el mismo domicilio, moría Gala en 1964, último miembro de la estirpe en desaparecer. Por su parte, la segunda hija de la escritora, Aura, fallecía en 1942 en Carmona (Sevilla). Su esposo, Francisco Prats, moría en 1949 también allí. Los restos mortales de ambos fueron trasladados al panteón familiar de San Amaro en A Coruña, en donde reposan desde 1949 (Naya 1974: 31; 1998: 153).

17 Visión estereotipada del muchacho que crece rodeado de religiosos y peregrinos. En el relato de este viaje mítico se narran numerosas peripecias. En esencia semeja ajustarse al tópico del homo viator, al tiempo que parece tener bastante analogía 
el mar con la finalidad de encontrar el Paraíso Terrenal, en lo que es a todas luces un repetido tema legendario transfronterizo. Es más, puestos a buscar concomitancias, habría que reparar en la iglesia de Santiago de Padrón (A Coruña) -nótese la relación de la escritora con esta villa y su relación con el tema jacobeo-, al existir allí un altar dedicado a la devoción de San Amaro.

De Amara se ha dicho que tenía por costumbre vestir de blanco $^{18}$ (Naya 1974: 41; 1998: 160), al igual que el célebre Amaro ${ }^{19}$ el peregrino ${ }^{20}$, indumentaria que en la leyenda le entrega Brígida ${ }^{21}, \mathrm{ni}$ más ni menos que una de las patronas de Irlanda.

También es comúnmente aceptado que en torno a la figura de San Amaro coexisten varias tradiciones paganas cristianizadas y que se relacionan con los denominados immrama ${ }^{22}$ irlandeses o relatos sobre viajes marítimos. En consecuencia, esta misma fuente de inspiración habría servido para hilar en sus comienzos la famosa leyenda medieval de la Navigatio Sancti Brendani Abbatis o La Navegación del abad San Brendano. En ella no sorprende encontrar alusiones al "mar del Oeste" (1995: 9) y a que Brendano "partió hacia el mar de Occidente con catorce hermanos" (1995: 12), esto es, en lo que geográficamente podría representar el lugar que hoy conocemos como la ciudad de A Coruña, en aquella época concebida como un punto limítrofe occidental.

con la figura del conquistador, un motivo temático reiterado en la historia de la literatura.

${ }^{18}$ Rosalía de Castro empleaba el topónimo Albión para referirse, de forma culta y por extensión, a Inglaterra, "iDescansa en paz, descansa en paz, ouh Moore! / E vós que o amás, do voso honor celosos, / fillos de Albión, permanecei tranquilos" (Castro 1993: 2, 343). Alguna teoría sobre su origen léxico hace hincapié en que habrían sido los romanos los que más influyeron en que este nombre evolucionase como derivación de su albus, es decir, blanco. No es difícil relacionar lo anterior con lo que tal vez fue la primera impresión visual de los famosos acantilados de Dover, en el condado de Kent, sureste de Inglaterra.

19 También existió el castillo de San Amaro, batería defensiva probablemente del siglo XVI (vid. Villaroel 1810). Igualmente hay en A Coruña la playa de San Amaro en la que, por cierto, se ahogó un coetáneo y amigo de Rosalía de Castro y de Manuel Murguía, el compostelano Aurelio Aguirre (1833-1858).

20 Todo indica que el acta de nacimiento del mito haya que buscarla en la vida del penitente francés del siglo XIII, quien viajó a Santiago de Compostela y a su regreso se instaló en Burgos para dedicar su vida a la atención de peregrinos y de enfermos pobres. En la leyenda tradicional gallega se alude a la riqueza heredada a la muerte de sus padres y que decide "dedicarla a la creación de hospitales, asilos para los menesterosos y conventos" (Carré 1999: 96).

${ }^{21}$ Irlandesa cuya vida trascurrió entre los siglos V y VI. Su nombre viene del gaélico Brighid o Bridgid, puede que en referencia a la diosa celta del fuego.

${ }^{22}$ En las antiguas sagas irlandesas y en el Book of Leinster se mencionan siete immrama, aunque solo se conservan tres, The Voyage of Mael Dúin, The Voyage of the Uí Corra y The Voyage of Snédgus and Mac Riagla (vid. Alberro 2006). 
De igual manera, en las leyendas recogidas en los manuscritos medievales generados a lo largo de la geografía del arco Atlántico, en concreto en el irlandés Leahbar Gabhála o Libro de las invasiones de Irlanda, se alude al extremo occidental peninsular ibérico, es decir, a Galicia, a la punta de España, y más precisamente, a Brigantia, por lo tanto, a A Coruña.

Por su parte, algunas de estas leyendas irlandesas desarrollan una temática similar a la que se recoge en el códice del siglo XI Trezenzonii de Solistitionis Insula Magna. En este caso el protagonista es Trezenzonio, monje gallego a quien se le atribuye una serie de hazañas en la línea de lo inverosímil, tal y como resulta ser, por ejemplo, el avistamiento de la Gran Isla del Solsticio desde la Torre de Hércules $^{23}$ de A Coruña, aspecto que, de alguna manera, parece indicar una evidente conexión con las aventuras de Ith, hijo del caudillo celta Breogán.

\section{Jardín de San Carlos, lugar de inspiración}

Este lugar coruñés ${ }^{24}$, cercano a la calle del Príncipe y también al edificio de la Capitanía General en donde Manuel Murguía dirigía el Archivo Regional de Galicia, está ubicado frente a la bahía y el puerto, así que cuenta con una panorámica excepcional.

No parece una tarea complicada imaginar a Rosalía de Castro en este mirador ${ }^{25}$. Tal vez, alguna que otra mirada melancólica

${ }^{23}$ Datada en el siglo II, se cree que su finalidad prioritaria fue la de servir de faro de navegación. Según se registra en la inscripción conmemorativa, el arquitecto fue el lusitano Cayo Sevio Lupo. Esta simbólica construcción sirvió de fortificación en la época medieval, función que le acarreó un deterioro considerable. En el siglo XVII se procedió a su restauración y se añadió a su arquitectura la admirada escalera interior, "valiéndose para esta obra de un Arquitecto llamado Amaro Antunez, vecino de la Coruña" (Cornide 1792: 29), lo que estaría desvelando la existencia, de nuevo, del antropónimo Amaro en relación con la ciudad coruñesa.

${ }^{24}$ En la actualidad en una de las partes del Paseo Sir John Moore está ubicado el antiguo Hospital Militar de A Coruña que, desde 1996, lleva el nombre de Hospital Abente y Lago, en homenaje al que fuera su director y médico del Cuerpo de Sanidad Militar. Dar este dato aquí no pasaría de lo anecdótico, salvo que reparemos en los apellidos aludidos. Se refieren a Ezequiel Abente y Lago (18411923), nacido en Corcubión (A Coruña), lugar cercano a Muxía, en donde su padre, Leandro Abente Chans (1809-1896), también ejercía de médico, sin olvidar la circunstancia biográfica relativa a que era tío del escritor y médico Eduardo Pondal y Abente (1835-1917). En 1853 Rosalía de Castro fue invitada a pasar unos días en la casa de Leandro Abente por Eduarda Pondal, también sobrina del anfitrión, para asistir a la célebre romería de Nuestra Señora de la Barca de Muxía. Ambas enfermaron de tifus y, a consecuencia de esta afección, Eduarda Pondal falleció a finales del mes de septiembre.

25 A mayores, convendría tener en cuenta que este lugar estratégico coruñés le pudo haber propiciado otros momentos de inspiración estética, por ejemplo, la constante reivindicación acerca del dramatismo desencadenado por el proceso 
reposada en el horizonte pudo haber captado uno o varios instantes de creación artística, numen propicio en medio de esta atmósfera ecuórea.

La reputada escritora databa en 1871 en A Coruña el poema ${ }^{26}$ intitulado "Na tomba do xeneral inglés Sir John Moore", integrado en la obra lírica Follas novas (1880) y, hasta que no se demuestre lo contrario, única composición rubricada por ella en A Coruña.

De las ingentes opciones que existen, nos inclinamos por traer a estas líneas una descripción concisa y, a nuestro juicio, bastante acorde con la realidad del espacio en el que se da cobijo funerario al escocés Sir John Moore (1761-1809), objeto lírico rosaliano y también wolfiano. Así para el escritor y geógrafo ourensano Ramón Otero Pedrayo (1888-1976), el Jardín de San Carlos es "la flor de la ciudad, el lugar que concentra bellamente, con cierto desdén ante los cambios, los temas de la ciudad" (Otero 1954: 195).

Poco tiempo después de finalizar la Guerra de la Independencia española, John Moore ${ }^{27}$ ya aparecía retratado como un superhombre, "distinguished for his private virtues, and his military talents" (Sarrazin 1815: 358). Es más, todo apunta a que desde la misma noche del 17 de enero de 1809, cuando sus compatriotas le enterraron al pie de las murallas del Parrote ${ }^{28}$, la tragedia de John Moore estaba destinada a ser un versátil motivo de inspiración lírica.

migratorio coetáneo, un punto de apoyo esencial sobre el que se asienta una parte importante de la estructura literaria rosaliana.

26 Se lo dedicó a María Bertorini - de soltera María Margarita Jones-, esposa de Camilo Bertorini, el que fue gerente de The west Railway Galicia, la primera línea de ferrocarril que unió Santiago de Compostela con Carril (Vilagarcía de Arousa, Pontevedra). Años después, el bisnieto de la destinataria del poema, el premio Nobel Camilo José Cela (1916-2002), natural de Iria Flavia (Padrón, A Coruña), comentaba que "fue Rosalía, la dulce Rosalía, el alto poeta que quiso dedicar a mi bisabuela María Bertorini, a miñ'amiga María Bertorini, nativa d'o país de Gales, los versos que compuso para ser grabados n'a tomba d'o xeneral inglés sir John Moore, morto n'a batalla d'Elviña (Coruña) o 16 de xaneiro de 1809" (Cela 1957). Tomamos la cita de López y Pociña (1991: 186); según explican los autores, este trabajo de Cela, datado en 1953, apareció con el título "Padrón, Padrón, Santa María, Lestrove..." y vio la luz en el periódico Faro de Vigo. Con posterioridad se incluyó en Cajón de sastre (1957).

${ }^{27}$ Este general se encontraba en A Coruña con la intención de embarcar las tropas británicas hacia el Reino Unido para evitar lo que parecía irremediable, es decir, que les diesen alcance los franceses dirigidos por Jean de Dieu Soult (1769-1851). Sin embargo, John Moore el 16 de enero de 1809 cayó herido en el lugar coruñés de Elviña, desde donde fue trasladado a la casa propiedad de Genaro Fontenla, en el número 13 del Cantón Grande, en donde falleció.

28 Este simbólico espacio urbano aparece registrado en el poema de temática migratoria "iPra A Habana!" de Follas novas: "De humanos seres a compauta linea / que brila ó sol adiántase e retórcese, / mais preto e lentamente as curvas sigue / do murallón antigo do Parrote" (Castro 1993: 2, 406). 
Parece ser que este sitio era un peñascal abandonado, hasta que se proyectó crear un jardín en 1834 en cuyo centro se colocó el sepulcro de John Moore, "un cuadrilátero de granito gallego con los ángulos almohadillados [...] en las dos caras norte y sur del sepulcro hay dos tarjetas y en ambas la siguiente inscripción Joannes Moore / Exercitus Britannici Dux / proelio occisus / A.D. 1809" (Vedía 1845: 293).

Al lado derecho del mirador de San Carlos se encuentran veintidós versos extractados del poema original de Rosalía de Castro. En la lápida conmemorativa leemos:

iCuan lonxe, canto das escuras nebras

Dos verdes pinos, das ferventes olas

Qu'o nacer viron!..; dos paternos lares

Do ceo da patria, qu'o alumou mimosa

Dos sitios iay! do seu querer: que lexos

Víu á caer baix'enemigo golpe

Pra nunca mais se levantar, coitado!

Mais que fermosa e sin igual morada

Lle coup'en sorte ós teus mortales restos...

C'o seu respeto compasiva vela

Pol-o estranxeiro á quen traidora norte

Fixo fincar lonxe dos seus, a á alleos

Víu á pedir o derradeiro asilo.

Cando do mar atrevesés as ondas

Y o voso hirman á visitar veñades

Poñé na tomba o cariñoso oído

E se sentís rebuligar as cinzas

E s'escoitás indefinibres voces

E s'entendés o que esas voces digan

A y-alma vosa sentirá consolo

iEl vos dirá qu'arrededor do mundo

Tomba millor qu'aquí atopou n'achara

Senon dos seus antr'o amoros abrigo.

Sin duda se trata de una composición de tono elevado y de expresión culta. Este epitafio ha sido considerado por algunas voces críticas como una de las más "ambiciosas empresas de Rosalía" (Davies 1987: 355) y a través del que "su voz se hace majestuosa, digna, y procura la clásica y grave andadura del endecasílabo blanco" (Mayoral 1974: 550). 


\section{John Moore: ¿̇héroe o villano?}

Tradicionalmente se ha atribuido la responsabilidad creativa del texto panegírico "The burial of Sir John Moore at Corunna" $(1817)^{29}$ al poeta irlandés Charles Wolfe (1791-1823). Un fragmento ${ }^{30}$ de esta composición elegíaca dedicada al héroe convive con los versos que Rosalía de Castro le dedicó también al general caído en A Coruña, ambos homenajes líricos cincelados en la heroicidad marmórea "con plumas de ave ligera" (Gallego 1946: 1).

Como si se tratase de formas geométricas de proporciones áureas, en el lado derecho del acceso al mirador del Jardín de San Carlos están emplazados los versos de la poeta compostelana, mientras que en el flanco izquierdo está situada la parte correspondiente del poema de Charles Wolfe ${ }^{31}$ :

Not a drum was heard, nor a funeral note, As his corse to the rampart we hurried; Not a soldier discharged his farewell shot O'er the grave where our hero we buried.

We buried him darkly at dead of night, The sods with our bayonets turning, By the struggling moon beam's misty light And the lantern dimly burning.

No useless coffin enclosed his breast, Nor in sheet nor in shroud we bound him; But he lay like a warrior taking his rest, With his martial cloak around him.

Few and short were the prayers we said, And we spoke not a word of sorrow;

But we stead fastly gaz'd on the face of the dead, And we bitterly thought of the morrow.

Slowly and sadly we laid him down, From the field of his fame fresh and gory; We carv'd not a line, we rais'd not a stone, But we left him alone with his glory.

${ }^{29}$ Con motivo de cumplirse el centenario de la muerte de John Moore, el coruñés Francisco Tettamancy (1854-1921) tradujo este poema a la lengua gallega y se lo dedicó al escritor Manuel Curros Enríquez (1851-1908), cuyos restos reposan en el cementerio coruñés de San Amaro. Véase "O enterro de Sir John Moore (de Charles Wolfe)" en Vida Gallega, 1/1/1909.

${ }^{30}$ La composición está formada por ocho estrofas de cuatro versos cada una. En la placa homenaje se esculpieron las cuatro primeras y la última.

${ }^{31}$ Hay una publicación que reúne la traducción del poema al español, entre otras cosas (vid. Atencia 1986). 
Según algunos críticos, el londinense lord George Byron (17881824) habría rescatado del pasado este poema de Charles Wolfe para darle una divulgación adecuada a su contemporaneidad, toda vez que cualquier signo literario de exaltación patriótica estaba destinado a triunfar, algo muy en consonancia con el prototipo del héroe ${ }^{32}$ y del escritor románticos.

Asimismo, se ha debatido mucho sobre el patriotismo y las proezas de John Moore en suelo gallego, a veces desde posturas con evidentes tics y ornatos hiperbólicos, algo previsible a poco que indaguemos en la heurística sobre la creación y la divulgación de las gestas, a menudo acomodaticias al devenir de la contemporaneidad histórica y literaria. Tal es así que con este asunto se generó un continuo vaivén político de posiciones enfrentadas en el Parlamento inglés acerca de la valentía o de la cobardía de las acciones del general británico en A Coruña.

Por ello, ante una situación de este tipo en la que encontrar el casus belli no parece accesible desde actitudes dogmáticas, lo más ecuánime podría estar en la sencilla praxis de recoger con cierta cautela la información tanto de sus más entusiastas defensores como de sus más acérrimos detractores, lo que nos dejaría ante una nítida y razonable conclusión a priori: tanto franceses como británicos consiguieron sus respectivos fines, a costa, eso sí, de relativizar los medios empleados para ello. Las tropas británicas embarcaron rumbo al Reino Unido, lo que pretendía John Moore, mientras que las huestes napoleónicas lideradas por Jean de Dieu Soult se hicieron con la ciudad de A Coruña.

Lo que sí parece estar claro es que hubo una época en la que imperó cierto desagrado por parte de la opinión popular británica al respecto, no tanto por verse perdedora de la Batalla de Elviña, sino más bien por las consecuencias que la derrota había ocasionado en general a su estrategia militar. Parece ser que el Reino Unido había visto en el territorio peninsular español un abonado campo de batalla en el que tenía todo a su favor para vencer a Francia. Retirar las tropas que mandaba John Moore en A Coruña significaba comprometer las vidas de muchos de los 12.000 soldados ingleses que, dirigidos por Sir Arthur Wellesley (1769-1852), duque de Wellington y de Ciudad Rodrigo, estaban en suelo portugués. Incluso llegó a hablarse de investigar las posibles responsabilidades que, de haber sido el desenlace de otra manera, habrían sido depuradas por un juzgado militar: "La retirada de las tropas británicas á su país, fue de un efecto tal, que no podemos dudar un momento de que, si Sir

${ }^{32}$ Falleció en el campo de batalla entre los insurgentes griegos que combatían por su independencia. 
John Moore desembarca con sus soldados en el Reino Unido, hubiera comparecido ante el tribunal militar" (Morillo 1911: 182).

Por su parte, según consta en el Libro de Actas de 1809 de A Coruña, el mismo día de la Batalla de Elviña, John Moore notificaba el embarque de sus tropas hacia el Reino Unido, y justificaba dicho acto en no haber encontrado "Ios auxilios y el patriotismo que esperaba":

El General Ingles More habia hecho pres. ${ }^{\text {te }}$ al mismo Reyno, q. ${ }^{\text {e }}$ la venida de los Exercitos, mas auxilios y mas patriotismo, y que mediante nada de esto habia encontrado en este Reyno habia resuelto reembarcarse con su Exercito, ofreciendo que este guardaría la mejor disciplina, y que esperaba no se le incomodase $p .^{r}$ parte de los vecinos con lo qual se ebitarian los perjuicios respectivos y con su vista acordó la Ciud. ${ }^{\mathrm{d}}$ que sobre esta materia nada ti. ${ }^{\mathrm{e}} \mathrm{q} .{ }^{\mathrm{e}}$ resolver y asi lo acordaron y firman de q. ${ }^{e}$ certifico. (Vaamonde 1909: 126)

César Vaamonde Lores sacaba a la luz este documento de vital importancia para el conocimiento de nuestro pasado. Su postura no deja lugar a dudas, y se muestra contundente con la actitud de John Moore respecto a España, en general, y a Galicia, en particular, al comentar en nota a pie de página:

No sabemos si la conducta de Sir John Moore motejando de antipatriota a nuestro Reino estará muy en consonancia con los desvelos y sacrificios que Galicia se impuso por él y por su ejército; con los homenajes que la Coruña siempre le ha tributado; y con el respeto y veneración con que aun hoy se recuerda su memoria en nuestra ciudad. (Vaamonde 1909: 126)

Asimismo, no estaría de más valorar con cierta vocación objetiva y con el merecido detenimiento que este asunto merece otro tipo de informaciones publicadas acerca del comportamiento que tuvieron algunos miembros de las tropas inglesas a su paso por localidades como, por ejemplo, Lugo. El 10 de enero de 1809 se informaba que los ingleses apuraban al máximo su retirada y que en esta ciudad gallega:

Los ingleses han dexado aqui 300 enfermos y 18 cañones. En esta ciudad han matado 700 caballos que no podían llevarse consigo. El duque de Dalmacia debe estar hoi en Betanzos, á pocas leguas de la Coruña. El mejor espíritu reina en los habitantes de Galicia; y el obispo y clero de Lugo no se han movido de aquí. Los ingleses han saqueado á la ciudad, la que ha sufrido mucho quando estos se retiraron, pues que se entregaban á todos los excesos imaginables. (Gazeta de Madrid, 16/1/1809) 


\section{Conclusiones}

Uno de los más autorizados y fidedignos biógrafos de Rosalía de Castro decía de ella que les hablaba a sus hijos de A Coruña como si fuese

una ciudad encantada, de aquellas que se mencionan en los cuentos mágicos con las campanas de plata que en las calles dejan oír sus sones, de las puertas de oro que dan feliz entrada al viajero, de las soñadoras puestas de sol en que éste se sumerge con un chisporroteo enorme sobre las aguas del mar. (Naya 1956: 4)

Desde una perspectiva analítica, la categoría estética de un mundo fantástico en el que se coloquen hechos inexplicables dentro de las leyes espaciales y temporales, podría estar permitiendo el acceso a un ámbito interpretativo marcadamente innovador en relación con la trayectoria rosaliana a su paso por la ciudad de $\mathrm{A}$ Coruña.

Tal y como se ha ido comentando a lo largo de este artículo, los momentos biográficos de la escritora en la ciudad de A Coruña parece ser que estuvieron condicionados a las discontinuas estancias profesionales de su esposo, debidas bien a su labor periodística bien a su profesión de archivero.

Con todo, a juzgar por los escasos testimonios en primera persona que se conservan o que han traspasado la oscuridad y el silencio de los ámbitos privados, A Coruña para Rosalía de Castro parece que fue un lugar preferente y que le despertaba bastante simpatía y un manifiesto confort, a lo que habría que añadirle la particularidad positiva de ser, en condiciones normales, un sitio benevolente en lo que se refiere a climatología.

También un resultado interesante que conviene referir aquí es el relativo al rol determinante que desarrolla un preciso espacio coruñés en los procesos de inspiración y de creación del texto lírico dedicado al general John Moore. Debe notarse, por tanto, que todo apunta a que fue este lugar estratégico, y no otro, el que habría propiciado un momento estético para elogiar el patriotismo del héroe y llevar a cabo su entronización.

De esta forma, el valor histórico y artístico de las murallas, puerta del Parrote y el propio Jardín de San Carlos propició que se declarase el 9 de noviembre de 1944 Monumento Histórico Artístico el conjunto constituido por las siguientes zonas de A Coruña:

Primero. - La antigua puerta llamada del Parrote, junto a la Capitanía General, y el trozo de muralla del siglo XIV que respalda la calle de San Carlos y sirve de base al jardín de este nombre.

Segundo.- El jardín de San Carlos, en el que se conserva el mausoleo del general inglés sir John Moore; y 
Tercero.- La zona de murallas de los siglos XVI al XVIII, comprendidas entre la caseta del centinela de la Capitanía General, con sus notables puertas del Parrote, del Clavo y de San Miguel, hasta dar vuelta a la rotonda del Hospital Militar, a contar desde la puerta de San Miguel. (Boletín Oficial del Estado, 18/11/1944)

Parece, pues, que la relación temporal y espacial en conexión con este lugar observado tendría calidad de nutriente artística en algunos textos literarios rosalianos.

Como una peregrina más, Rosalía de Castro llegaba desde Madrid, el este si nos situamos en Galicia, para instalarse en A Coruña y dar vida allí a su hija Amara. Tal vez, ella ya había encontrado su Paraíso, su Tierra Prometida, no tanto como peregrinatio forzosa y expiatoria del medievalismo más ascético, sino más bien como una voluntaria vuelta a casa en el sentido más moderno del término.

Por todo lo visto, parece confirmarse que el tiempo sí se comprime y también se hace visible desde el punto de vista artístico (Bajtin 1989), y simultáneamente el espacio se intensifica, al tiempo que, de alguna manera, se acrecienta. En visión analéptica conseguimos recuperar momentos estáticos y estéticos que se revelan a través del espacio de la ciudad de A Coruña, lo que permite que este mismo espacio sea descifrado y calibrado a través del tiempo.

En síntesis, según la teoría especial de la relatividad defendida por el alemán Albert Einstein (1879-1955), y de la que se nutre Bajtin, la percepción del espacio y del tiempo depende del estado de movimiento o es relativa al observador, algo que parece confirmarse en el caso expuesto de la escritora Rosalía de Castro y su relación con la ciudad de A Coruña, en general, y de determinados espacios dentro de ella, en particular.

Además de la paronomasia que ya se evidencia en el título de este artículo, no está de más volver a recurrir a la adnominatio para lanzar al aire la idea relativa a que, quizá, Amaro el peregrino, Amara Martínez de Castro y la lectura palindrómica de la parte inicial de la palabra de los immrama podrían tener en común algo más que una combinación aleatoria de lexemas. 


\section{Bibliografía}

ALBERRO, Manuel (2006): Paradigmas de la cultura y la mitología célticas. Gijón: Trea.

ALONSO ROMERO, Fernando (1991): Santos e barcos de pedra: para una interpretación da Galicia Atlántica. Vigo: Xerais.

ATENCIA, María Victoria (1986): "Moore (tres poemas)". Actas do Congreso internacional de estudios sobre Rosalía de Castro e o seu tempo. Santiago de Compostela: Consello da Cultura Galega-Universidade de Santiago de Compostela, tomo II, pp. 401-410.

BAJTIN, Mijaíl (1989): Teoría y estética de la novela. Madrid: Taurus.

CARRÉ ALVARELLOS, Leandro (1999): Las leyendas tradicionales gallegas. Madrid: Espasa Calpe.

CASTRO, Rosalía de (1993): Obras Completas de Rosalía de Castro, edición de Marina Mayoral. Madrid: Turner, 2 vols.

CELA, Camilo José (1957): Cajón de sastre. Madrid: Alfaguara.

CORNIDE, Joseph (1792): Investigaciones sobre la fundación y fábrica de la Torre llamada de Hércules, situada á la entrada del puerto de la Coruña. Madrid: Oficina de Benito Cano.

DAVIES, Catherine (1987): Rosalía de Castro no seu tempo. Vigo: Galaxia.

GALLEGO, Juan María (1946): "Dos poetas en torno a sir John Moore". El Progreso, Lugo, 6/7/1946.

GARCÍA VEGA, Lucía (2010): "Rosalía de Castro e Madrid. Análise literaria dos lugares na novela El caballero de las botas azules (1867)". Moenia, núm. 16, pp. 195-245.

- (2011): "Rosalía de Castro agonista. Diálogos protagonista y antagonista con la ciudad de Santiago de Compostela" [en línea]. En: Ángulo Recto. Revista de estudios sobre la ciudad como espacio plural, vol. 3, núm. 2, pp. 51-67. En: http://www.ucm.es/info/angulo/volumen/Volumen03-

2/articulos04.htm. ISSN: 1989-4015. http://dx.doi.org/10.5209/rev ANRE.2011.v3.n2.37579

LÓPEZ, Aurora; y POCIÑA, Andrés (1991): Rosalía de Castro. Documentación biográfica y bibliografía crítica (1837-1990). A Coruña: Fundación Pedro Barrié de la Maza, vol. II (1941-1984).

LÓPEZ MORILLO, Adriano (1911): "Un documento histórico poco conocido. Discurso leído en la sesión celebrada en Vigo el 17 de noviembre de 1910 para su recepción como Académico de Número". Boletín Real Academia Gallega, núm. 44, pp. 173-192.

MAYORAL, Marina (1974): La poesía de Rosalía de Castro. Madrid: Gredos.

Navigatio Sancti Brendani Abbatis (1995). Trad. José Manuel Álvarez Flórez. Madrid: Anaya \& Mario Muchnik.

NAYA PÉREZ, Juan (1953): Inéditos de Rosalía. Santiago de Compostela: Publicaciones del Patronato Rosalía de Castro.

- (1956): "Rosalía de Castro y La Coruña". Hoja del Lunes, A Coruña, 13/8/1956.

- (1974): "El final de una estirpe: Rosalía de Castro y Manuel Murguía". Boletín Real Academia Gallega, núm. 356, pp. 25-49.

- (1998): Estudios acerca de la familia Murguía-Castro. A Coruña: Deputación Provincial da Coruña.

OTERO PEDRAYO, Ramón (1954): Guía de Galicia. Vigo: Galaxia. 
POCIÑA, Andrés; y LÓPEZ, Aurora (2000): Rosalía de Castro. Estudios sobre a vida e a obra. Santiago de Compostela: Laiovento.

SANTOS GAYOSO, Enrique (1990): Historia de la Prensa Gallega 18001986. Sada (A Coruña): Do Castro.

SARRAZIN, Jean (1815): History of the War in Spain and Portugal from 1807 to 1814 . London: Henry Colburn.

SOTO FREIRE, Manuel (1982): La imprenta en Galicia. Lugo: Círculo de las Artes.

TETTAMANCY Y GASTÓN, Francisco (1909): "O enterro de sir John Moore (de Charles Wolfe)". Vida Gallega, A Coruña, 1/1/1909.

VAAMONDE LORES, César (1909): "El general inglés Sir John Moore, notifica a nuestro Reino, que mediante no encontrara los auxilios y el patriotismo que esperaba, había resuelto reembarcarse con todo su ejército (1809)". Colección de documentos históricos de la Real Academia Gallega, vol. 3, pp. 125-126.

VEDÍA Y GOOSSENS, Enrique de (1845): Historia y descripción de la ciudad de A Coruña. A Coruña: Imprenta y librería de D. Domingo Puga.

VILLAROEL, José de (1810): Diccionario nomenclátor de las ciudades, villas, aldeas, caserías, cotos, ventas, castillos, y prioratos de todo el Reyno de Galicia. Con expresión de las provincias á que pertenecen, y caxas de correo por donde se dirige la correspondencia; á que se agrega una descripción geográfica-histórica del mismo Reyno en general, y de todas sus ciudades, y pueblos principales en particular. Santiago de Compostela: Juan Francisco Montero. 